\title{
SEVERAL ECOLOGICAL ASPECTS OF THE HYMENOPTERA COMPLEX IN A PLUM ORCHARD (II)
}

\author{
Eliseev,S.E.,Sumencova V. V., Iordosopol E. I. \\ Institute of Genetics, Physiology and Plant Protection, Chișinău, serghei_eliseev@yahoo.com \\ https://doi.org/10.53040/9789975347204.05
}

\begin{abstract}
The present paper treats several ecological peculiarities of the hymenopteran complex in a plum orchard. The intense flight activity for Hymenoptera complex was observed in the second half of the vegetation season starting from the first decade of August as a result of stopping phytopharmaceutical treatments. The most number of specimens was registered in four families. Parasitoids ocuppy $89.0 \%$ out of all Hymenoptera, being of great importance for plant protection. Hymenoptera form $21.0 \%$ out of total plum canopy fauna number in 2017 . They occupy the second place in total fauna number. The percentage of Hymenoptera out of total arthropods' number is $66.0 \%$, the rest beneficial mesofauna has just $34.0 \%$ in 2017.
\end{abstract} ratio.

Key words: Hymenoptera, parasitoid wasps, plum, flight dynamics, Hymenoptera/Insecta

\section{Introduction}

Hymenoptera is a large order of Insects with a worldwide spread. The vast majority of them are widely known by human e. g. bees, ants and wasps. They play a significant role in nature, being both beneficial (bees polinating the flowers and supplying human with honey, parasitoid wasps exterminating serious agricultural pests) and noxious (sawflies affecting different cultures).

According to Dhaliwal, Jindal and Mohindru (2015) one-fifth of the worldwide annual crops production is destroyed by herbivorous insects [1]. Plum plantations suffer annualy from the number of pests, mostly several species of moths, sawflies and aphids.

The wide number of parasitoid wasps with a correct pesticide appliance could reduce significantly damages produced by these complex of pests. 
The aim of the present paper is to elucidate several ecological aspects of the Hymenoptera complex in a plum orchard. Thus, flight dynamics, nutritional strategies and Hymenoptera/Insecta ratio, were studied in a treated plum orchard's conditions.

\section{Materials and methods}

Multiannual plum orchard consisting of Cacanska rana and Stanley varieties was chosen for the study. This orchard is situated in the Băcioi village (Chisinau vicinity, Republic of Moldova).

Plum orchard used to be treated with different phytopharmaceuticals starting from early spring till the middle of June against fungi, weeds and Hoplocampa spp. complex (Hymenoptera: Tenthredinidae).

We used yellow sticky traps hung in a middle of a plum tree crown to collect insects during vegetation season. The present paper is a continuation of the similar work [2] done in 2016 and covers 2017 vegetation season. Twelve yellow sticky traps were hung once in two weeks covering 11.04.2017 to 22.08.2017. Every two weeks the traps were examined in the laboratory conditions using microscopy with 4.5 x 10 magnification. The exemplars were keyed till the family taxa. "Hymenoptera of the world: an identification guide to families" [3] was used as a key.

\section{Results and discussion}

Uneven nature of the flight dynamics is specific for the Hymenoptera flight dynamics of the given vegetation season (fig. 1). The most spectacular dynamics is manifested in two families - Mymaridae and Ceraphronidae in both 2016 and 2017. There are two peaks in Mymaridae in 2017. One of these peaks is specific for the third decade of April, another - for the first decade of August. Between them lies the space with the massive pesticide usage where Mymaridae dynamics is at its lower points. In 2016 the situation is similar, but the numbers start to rise in the first decade of July and continue till the last observation data in the first decade of September. Ceraphronidae had one peak in 2017 in the first decade of August after all the pesticide usage was done. The diagram shows that exponential growth in specimens' number starts after massive pesticide pressing is gone. Four families showed the most spectacular flight: Mymaridae, Ceraphronidae, Platygastridae and Encyrtidae.

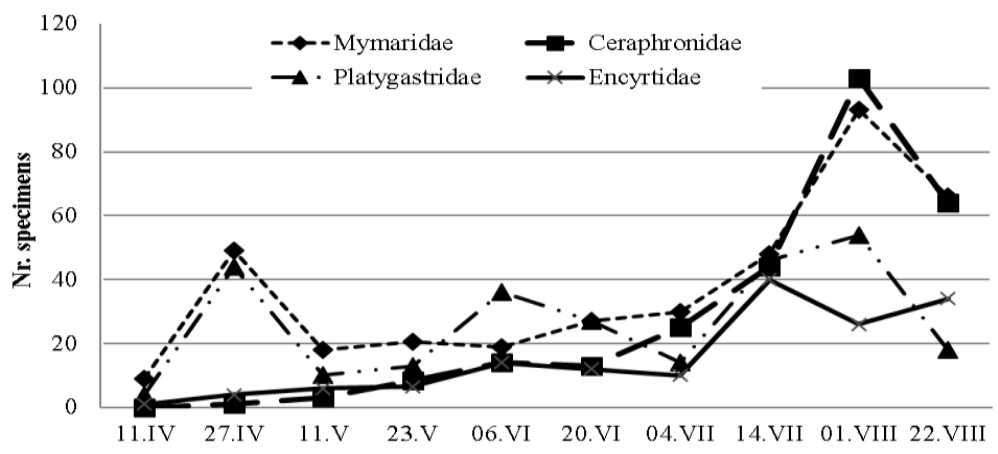

Fig. 1. The dynamics of the top four Hymenoptera families in the plum orchard (2017)

Parasitoid wasps' specimens appear in the early spring along with the pests (sawflies). Six families: Mymaridae (oophages parasitoids of Homoptera and Hemiptera), Platygastridae (solitary hyperparasitoids of insects' and spiders' eggs), Encyrtidae (endoparasitoids of Coleoptera, Hemiptera, Lepidoptera, Diptera), Cynipidae (herbivorous), Pteromalidae (Homoptera, Neuroptera, Coleoptera and Diptera hyperparasitoids), Megaspilidae 
(Homoptera, Neuroptera and Diptera parasitoids) emerge when first observations were made in April. The majority of families appear massively in the third decade of April. Other families emerge late, e. g. Torymidae (ectoparasitoids of Cynipidae and Cecidomyiidae), Bethylidae (consume Coleoptera and Lepidoptera) and Diapriidae (Diptera endoparasitoids), Chrysididae (its larvae parasites on egg or larvae of other insects or cleptoparasites in insects' nests), Signiphoridae (Homoptera parasitoids) just in June, Jule and August. There are, also, several exotic families present, e. g. Liopteridae (Coleoptera: Buprestidae; Hymenoptera: Siricidae parasitoids), Figitidae (Eucoilinae; endoparasitoids of Diptera larvae) that were present sporadically just in a second decade of July.

According to present paper, parasitoids share $89.0 \%$ out of all Hymenoptera, thus showing its primordial importance for plant protection. Comparing to 2016 in 2017 the number of herbivorous Hymenoptera is high (1.0\% and $8.0 \%$ respectively). Approximately $3.0 \%$ are occupied by mixed nutrition Hymenoptera in 2017.

Plum orchards canopy would be much more austere without Hymenoptera, as they form $21.0 \%$ out of this microecosystem population. Hymenoptera occupy the second place in total fauna number, ahead them are just Diptera. The massive spread of Homoptera (aphids) makes up a strong nutrition resource for Hymenoptera (fig. 2). The beneficial insects' fauna of the plum trees' canopy includes $23.0 \%$, harmful insects' share 38.0\% (much more comparing to previous year $18.0 \%$ ), insects with neutral status form 39.0\%. In 2017 the percentage of Hymenoptera out of total arthropods' number is $66.0 \%$, all the rest beneficial mesofauna having just $34.0 \%$.

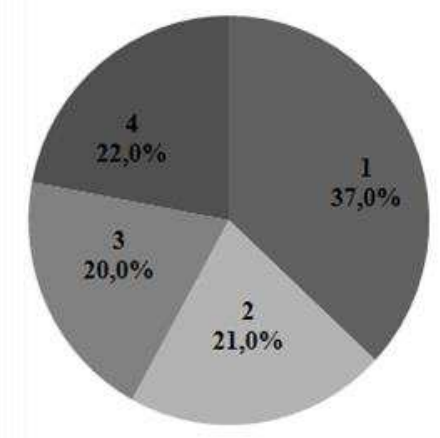

I. Diptera $=2$ 2. Hymenoptera $\mathbf{m}$ 3. Hemiptera $\mathbf{w}$ 4. Others

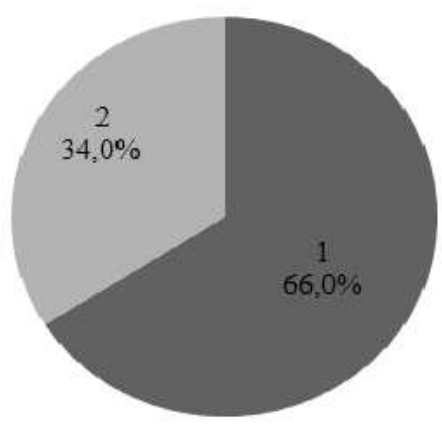

1. Hymenoptera 2 . Others

out of total number of ben eficial arthropods

Fig. Fig. 2. Hymenoptera share (\%) in trees' crown in the plum orchard (2017)

\section{Conclusions}

1. The intense flight activity for Hymenoptera complex was marked in the second half of the vegetation season starting from the first decade of August as a result of stopping phytopharmaceutical treatments. The most number of specimens was registered in four families.

2. Parasitoids ocuppy $89.0 \%$ out of all Hymenoptera, showing its major importance for plant protection.

3. Hymenoptera form $21.0 \%$ out of total plum canopy fauna number in 2017. Hymenoptera occupy the second place in total fauna number.

4. The percentage of Hymenoptera out of total arthropods' number was $66.0 \%$, all the rest beneficial mesofauna having just $34.0 \%$ in 2017 . 


\section{Bibliografi}

1. Dhaliwal G. S., Jindal V., Mohindru B. Crop losses due to insect pests: global and indian scenario. Indian Journal of Entomology. 77 (2): 165-168 (2015).

2. Eliseev S., Iordosopol E., Sumencova V. Several ecological aspects of the Hymenoptera complex in a plum orchard. "Protecția Plantelor în Agricultura Convențională și Ecologică”, 10 -12 decembrie 2018. Chișinău, p. 19-22, 2018.

3. Hymenoptera of the world: An identification guide to families. Ottawa, 1993, $670 \mathrm{p}$. ISBN 0-660-14933-8. 